\title{
Multiplicação in vitro e aclimatação de Vernonia condensata Baker
}

\author{
VICENTE, M.A.A.; ALMEIDA,W.A.B.; CARVALHO, Z.S. \\ Universidade Federal do Recôncavo da Bahia - UFRB, Caixa Posta 81, 44380-000-Cruz das Almas - BA, \\ *aliceargolo@yahoo.com.br
}

\begin{abstract}
RESUMO: A espécie medicinal Vernonia condensata, vulgarmente conhecida por alumã, pertencente à família Asteraceae, possui propriedades analgésicas e de proteção gástrica. A crescente utilização dessa planta no Nordeste, pelas propriedades terapêuticas, justifica a necessidade de medidas que minimizem o impacto de sua exploração nas reservas naturais. $\mathrm{O}$ objetivo desse trabalho foi multiplicar in vitro plantas de alumã sob diferentes concentrações de BAP e aclimatá-las. Gemas axilares foram desinfestadas em solução de álcool etílico 70\%, durante 2 minutos e em solução de hipoclorito de sódio ( $2 \%$ de cloro ativo) na concentração de 3:1, durante 15 minutos, seguido de três lavagens em água destilada estéril. Os tratamentos para multiplicação consistiram em doses de BAP $\left(0,0 ; 1,0 ; 2,0 ; 3,0 ; 4,0\right.$ e $\left.5,0 \mathrm{mg} \mathrm{L}^{-1}\right)$ em meio MS semi-sólido. $O$ delineamento experimental foi o inteiramente casualizado, com 5 repetições, contendo 10 gemas por repetição. Após 30 dias de cultivo observou-se maior taxa de explantes responsivos, $84 \%$ na concentração de $1,0 \mathrm{mg} \mathrm{L}^{-1}$ de BAP, com produção de 4,0 brotos/explante. Nos tratamentos 3,$0 ; 4,0$ e $5,0 \mathrm{mg} \mathrm{L}^{-1}$ ocorreu hiperhidricidade nas folhas. As microplantas de alumã provenientes da metodologia utilizada neste trabalho alcançaram $100 \%$ de sobrevivência na aclimatação.
\end{abstract}

Palavras-chave: biotecnologia, plantas medicinais, cultura de tecidos

\begin{abstract}
In vitro multiplication and acclimation of Vernonia condensata Baker. The medicinal species Vernonia condensata, commonly known as "alumã", belongs to the family Asteraceae and has analgesic and gastric protective properties. The increasing use of this plant in the Northeast of Brazil due to its therapeutic properties justifies the need of measures to minimize the impact of its exploitation in natural reserves. The aim of this study was to multiply, in vitro, "alumã" plants under different BAP levels, acclimating them. Axillary buds were sterilized in $70 \%(\mathrm{v} / \mathrm{v})$ alcohol solution for 2 minutes and in $75 \%$ sodium hypochlorite solution ( $2 \%$ active chlorine) at 3:1 concentration for 15 minutes, followed by three washings in sterile distilled water. Multiplication treatments consisted of different BAP levels $\left(0.0 ; 1.0 ; 2.0 ; 3.0 ; 4.0\right.$ and $\left.5.0 \mathrm{mg} \mathrm{L}^{-1}\right)$ in semi-solid MS medium. The experimental design was completely randomized, with 5 replicates and 10 buds per replicate. After 30 days of cultivation, the highest rate of responsive explants was obtained: $84 \%$ at $1.0 \mathrm{mg} \mathrm{L}^{-1}$ BAP, producing 4.0 sprouts/explant. In the treatments $3.0,4.0$ and $5.0 \mathrm{mg} \mathrm{L}^{-1}$, there were vitrified leaves. The "alumã" microplants used in this study had $100 \%$ survival in acclimation.
\end{abstract}

Key words: biotechnology, medicinal plants, tissue culture

\section{INTRODUÇÃO}

A espécie Vernonia condensata Baker, vulgarmente conhecida por alumã, pertencente à família Asteraceae, nativa possivelmente da África tropical, foi trazida ao Brasil nos tempos coloniais pelos escravos (Lorenzi \& Matos, 2002), que faziam uso da mesma por possuir propriedades analgésicas e de proteção gástrica (Boorhem, 1999).

A crescente utilização dessa planta medicinal no Nordeste, pelas propriedades terapêuticas, justifica a necessidade de medidas que minimizem o impacto de sua exploração nas reservas naturais. Portanto, a micropropagação parece ser uma alternativa viável,

Recebido para publicação em 05/05/2008

Aceito para publicação em 31/10/2008

Rev. Bras. PI. Med., Botucatu, v.11, n.2, p.176-183, 2009. 
pois permite a obtenção de um grande número de plantas com autenticidade varietal em qualquer época do ano (Nicoloso et al., 2001).

Quando se pretende explorar economicamente uma determinada espécie vegetal, o ponto de partida deve ser o estudo das formas de propagação e se elas apresentam viabilidade para o estabelecimento de um sistema produtivo (Scheffer, 1992).

Atualmente, muitas plantas medicinais já são multiplicadas in vitro. Entre elas: Pfaffia glomerata (Maldaner et al., 2006), Lychnophora pinaster(Souza et al., 2003), Jatropha elliptica (Campos et al., 2007), Aloe vera (Araújo et al., 2002), etc. Por meio da biotecnologia, é possível aumentar a produção e diminuir o preço dos princípios ativos fitoquímicos (Bajaj et al., 1988). A proliferação in vitro de plantas medicinais, a partir da cultura de gemas e meristemas, é basicamente uma extensão da propagação vegetativa feita em muitas espécies. Entretanto, este método pode ser usado não só para a produção de mudas sadias e de boa qualidade, mas também quando há escassez de material para o plantio (Cunha et al., 1999).

A cultura de tecidos de plantas é um método biotecnológico já consagrado pelos resultados alcançados em várias culturas, as quais foram beneficiadas pela produção de plantas uniformes e sadias, pela velocidade superior de crescimento em relação aos métodos convencionais de propagação, pela maior produção em menor tempo e espaço físico e, ainda pela obtenção de plantas livres de vírus e outros patógenos através da cultura de meristemas (Crócomo, 1986).

A indução de brotações in vitro ocorre pelo desequilíbrio hormonal induzido por uma concentração adequada e balanceada de reguladores vegetais adicionada ao meio, como a citocinina que é muito favorável na fase de multiplicação in vitro. A 6benzilaminopurina (BAP) tem sido muito eficaz para promover multiplicação de partes aéreas e indução de gemas adventícias em diversas espécies (Grattapaglia \& Machado, 1998).

Outro regulador vegetal utilizado no cultivo in vitro é o ácido giberélico $\left(\mathrm{GA}_{3}\right)$. $\mathrm{O}$ efeito mais conhecido das giberelinas in vitro é no alongamento das partes aéreas quando essas não estão em condições de serem individualizadas para o enraizamento, devido ao seu pequeno tamanho (Grattapaglia \& Machado, 1998).

As exigências nutricionais requeridas para o crescimento de um tecido em condições in vitro variam de espécie para espécie, de variedade para variedade e até mesmo dentro da própria planta, necessitando-se, assim, otimizar os meios de cultura (Nagao et al., 1994).

Uma etapa importante da micropropagação que inspira cuidado é a aclimatação. Um número expressivo de espécies vegetais cultivadas in vitro não sobrevive quando transferidas das condições in vitro para ambiente de casa de vegetação ou campo (Hararika, 2003). O sucesso da transferência de plantas em condições in vitro para a casa de vegetação é essencial para um sistema de micropropagação bem sucedido (Hoffmann, 2002).

Devido à importância desta planta para obtenção dos princípios ativos e outros múltiplos propósitos, objetivou-se induzir a multiplicação de brotos de alumã in vitro, através da adição dos reguladores vegetais BAP e $\mathrm{GA}_{3}$ ao meio de cultura, bem como aclimatá-los.

\section{MATERIAL E MÉTODO}

Plantas de alumã oriundas do campo foram utilizadas nesse trabalho. O experimento foi conduzido no Laboratório de Cultura de Tecidos de Plantas, do Centro de Ciências Agrárias, Ambientais e Biológicas da Universidade Federal do Recôncavo da Bahia (UFRB), em parceria com o Laboratório de Biotecnologia da Faculdade Maria Milza (FAMAM).

Desinfestação do material: Gemas axilares foram lavadas em água corrente e desinfestadas em solução de álcool etílico $70 \%$, durante 2 minutos. Em seguida foram imersas em solução de hipoclorito de sódio ( $2 \%$ de cloro ativo) e água na proporção de 3:1, durante 15 minutos em agitador magnético. $\mathrm{O}$ material vegetal foi lavado 3 vezes em câmara de fluxo laminar com água destilada e autoclavada.

Estabelecimento in vitro: Após o processo de desinfestação, as gemas foram inoculadas em placas de Petri contendo $20 \mathrm{~mL}$ do meio de cultura MS (Murashige \& Skoog, 1962), suplementado com $\operatorname{BAP}\left(0,0 ; 1,0 ; 2,0 ; 3,0 ; 4,0\right.$ e 5,0 mg L-1), $30 \mathrm{~g} \mathrm{~L}^{-1} \mathrm{de}$ sacarose e solidificado com ágar $(0,8 \%)$. $\mathrm{O} \mathrm{pH}$ do meio de cultura foi ajustado a 5,8, anteriormente à autoclavagem $\left(121^{\circ} \mathrm{C}\right.$ por 20 minutos). O experimento foi conduzido em B.O.D, com temperatura de $27 \pm$ $2^{\circ} \mathrm{C}$, fotoperíodo de 16 horas e $40 \mu \mathrm{mol} \mathrm{m}{ }^{-2} \mathrm{~s}^{-1}$ de intensidade luminosa. Após 15 dias de cultivo in vitro, avaliou-se a porcentagem de explantes responsivos (aqueles que formaram gemas e/ou brotos) nas placas e porcentagem de contaminação e oxidação.

Multiplicação in vitro: Os brotos obtidos nas placas foram transferidos para frascos contendo meio MS nas mesmas concentrações de $\operatorname{BAP}(0,0$; 1,$0 ; 2,0 ; 3,0 ; 4,0$ e $\left.5,0 \mathrm{mg} \mathrm{L}^{-1}\right)$ com o intuito de aumentar a taxa de multiplicação. Após 30 dias fezse a contagem dos brotos, os quais foram individualizados e colocados em novo meio de cultura MS, acrescido de $1 \mathrm{mg} \mathrm{L}^{-1} \mathrm{GA}_{3}$ e $1 \%$ de carvão ativado 
com o intuito de alongar e induzir a formação de raízes nas brotações. Ao final de 75 dias, avaliaram-se o número de folhas, comprimento de parte aérea, comprimento de raiz e porcentagem de sobrevivência.

Delineamento experimental: Para o estabelecimento e multiplicação in vitro o delineamento utilizado foi o inteiramente casualizado, com 5 repetições, contendo 10 gemas em cada repetição. Os dados obtidos na multiplicação foram analisados estatisticamente e submetidos à regressão e teste de Tukey.

Aclimatação: Foram selecionadas 100 microplantas, retiradas dos frascos e lavadas com água corrente com o objetivo de remover o excesso do meio de cultura. As microplantas foram acondicionadas em garrafas plásticas transparentes de refrigerante, de dois litros, com quatro pequenos furos na base para drenagem do excesso de água. As garrafas foram cortadas na metade de sua altura para facilitar a adição do substrato (terra vegetal autoclavada) e transplante da muda, após o que foram novamente fechadas por sobreposição das metades. No primeiro dia, no período matutino, retirou-se a cápsula (tampinha) da garrafa por 10 minutos, no segundo dia por 20 minutos e foi-se aumentando o tempo gradativamente até a retirada permanente da tampinha, quando as mudas já estavam adaptadas ao meio ambiente. Após trinta dias as mudas encontravam-se totalmente aclimatadas. Durante o período de aclimatação, as garrafas com as microplantas foram mantidas em telado com $30 \%$ de sombreamento e irrigadas com auxílio de um borrifador, de forma a manter a umidade relativa do ar elevada. Esta exposição progressiva das microplantas às condições ambientais teve o objetivo de reduzir o estresse. A porcentagem de sobrevivência foi avaliada ao final da aclimatação.

\section{RESULTADOE DISCUSSÃO}

Observou-se que a concentração de $1,0 \mathrm{mg} \mathrm{L}^{-1}$ de BAP foi aquela que promoveu o maior percentual de explantes responsivos (84 \%). Essa porcentagem de resposta diminuiu em concentrações maiores devido possivelmente ao efeito fitotóxico da citocinina (Figura 1).

Além da provável toxidez causada pela citocinina, as perdas obtidas durante a inoculação dos explantes de alumã no meio de cultura foram de 4 a $38 \%$, por contaminação com fungos e bactérias (Tabela 1). Segundo a análise estatística, aumentando-se as concentrações de BAP, aumentouse também a contaminação por bactérias nas gemas axilares de Vernonia condensata, interferindo na resposta morfogenética. É possível que as maiores

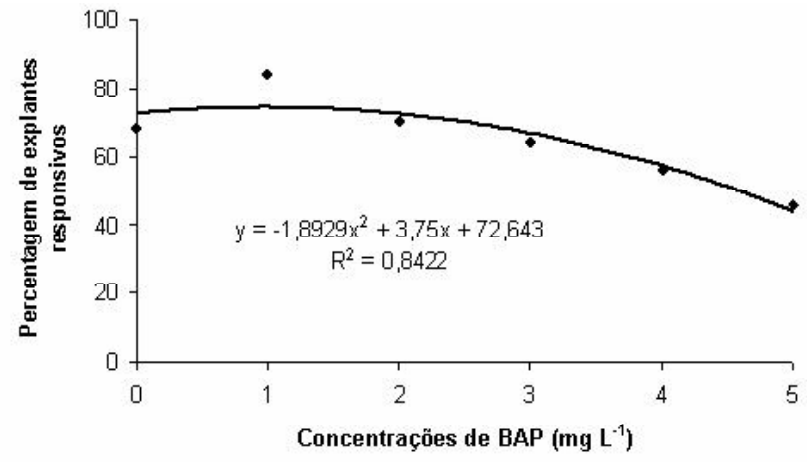

FIGURA 1. Porcentual de explantes responsivos de alumã em função de concentrações de BAP, após 15 dias de cultivo.

concentrações do regulador vegetal (BAP) tenham contribuído para aumentar a multiplicação de bactérias. Neste caso, necessita-se de estudos mais aprofundados para melhor avaliação dos efeitos do BAP no crescimento de bactérias, visto que não foram encontrados relatos na literatura da existência desta correlação. Entretanto, sabe-se que a contaminação é muito dependente do material vegetal utilizado para isolamento in vitro, que pode ser de casa de vegetação ou do campo. No caso da espécie Vernonia condensata, o material vegetal utilizado foi retirado de plantas do campo contendo elevada concentração de microrganismos. Segundo Tavares et al. (1992), uma maior destreza no isolamento dos explantes e a adoção de uma assepsia superficial mais efetiva, com emprego de uma maior concentração do agente esterilizante, maior período de tratamento ou utilização de outro composto desinfestante podem reduzir para níveis mais baixos as perdas aqui ocorridas.

Outro problema comum em cultura de tecidos é a oxidação de explantes, apesar do valor pequeno encontrado no presente trabalho (2 a 14\%), a qual interferiu também na resposta morfogenética dos explantes (Tabela 1). A oxidação ocorre em função da liberação de compostos fenólicos in vitro. Esses compostos fenólicos são oxidados, produzindo substâncias tóxicas que inibem o crescimento dos explantes, além de escurecer o meio de cultura (Grattapaglia \& Machado, 1998).

Com relação ao número de brotações por explantes, a concentração $1,0 \mathrm{mg} \mathrm{L}^{-1}$ de BAP foi aquela de melhor resposta, com 4,0 brotações/ explante, diferindo significativamente das demais concentrações (Figura 2). Resultado semelhante foi encontrado por Pasqual \& Ando (1989), no cultivo in vitro de gemas axilares de plântulas de Poncirus trifoliata, onde elevadas concentrações de BAP promoveram redução no percentual de explantes com brotações, sendo que a concentração ótima foi de $1,0 \mathrm{mg} \mathrm{L}^{-1}$ de BAP. 
TABELA 1. Porcentagem de perdas de explantes por contaminação e oxidação, após 15 dias de cultivo.

\begin{tabular}{cccc}
\hline $\begin{array}{c}\text { Concentração de } \\
\text { BAP }\left(\mathbf{m g ~ L}^{-1}\right)\end{array}$ & $\begin{array}{c}\text { Contaminação por } \\
\text { fungos }(\%)\end{array}$ & $\begin{array}{c}\text { Contaminação por } \\
\text { bactérias (\%) }\end{array}$ & $\begin{array}{c}\text { Oxidação de } \\
\text { explantes }(\%)\end{array}$ \\
\hline 0,0 & $10 \mathrm{a}$ & $8 \mathrm{a}$ & $14 \mathrm{a}$ \\
1,0 & $8 \mathrm{a}$ & $4 \mathrm{a}$ & $4 \mathrm{a}$ \\
2,0 & $14 \mathrm{a}$ & $10 \mathrm{ab}$ & $6 \mathrm{a}$ \\
3,0 & $14 \mathrm{a}$ & $16 \mathrm{ab}$ & $8 \mathrm{a}$ \\
4,0 & $8 \mathrm{a}$ & $28 \mathrm{bc}$ & $8 \mathrm{a}$ \\
5,0 & $14 \mathrm{a}$ & $38 \mathrm{c}$ & $2 \mathrm{a}$ \\
\hline
\end{tabular}

*Médias seguidas da mesma letra na coluna não diferem significativamente (Tukey 0,05 ).

Com relação à altura (comprimento da parte aérea) das brotações de alumã, não foi observado diferenças significativas entre as concentrações de BAP, embora a concentração de $1,0 \mathrm{mg} \mathrm{L}^{-1}$ tenha promovido a maior altura $(8,38 \mathrm{~cm})$, conforme Tabela 2. Segundo Grattapaglia \& Machado (1998), as citocininas estimulam a maior produção de partes aéreas das brotações até uma determinada concentração, a partir da qual ocorre diminuição da altura em virtude de um possível efeito fitotóxico da citocinina.

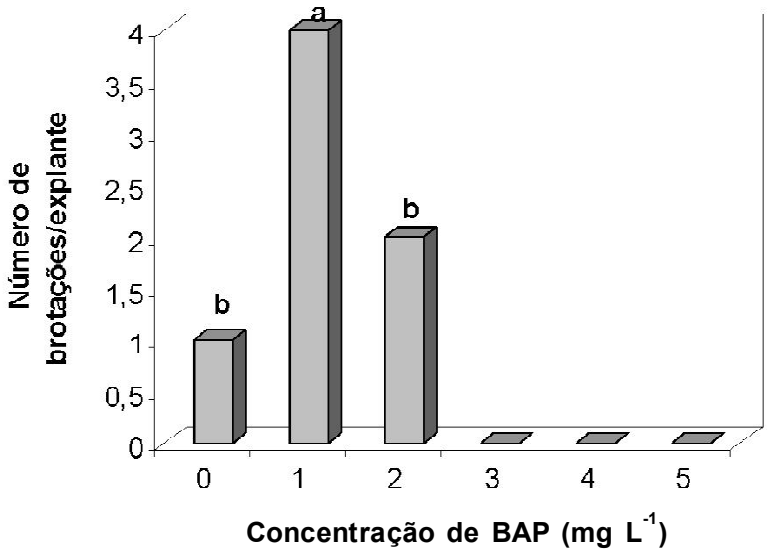

FIGURA 2. Número de brotações por explantes em função de diferentes concentrações de BAP, após 45 dias de cultivo.

A toxidez causada pelo excesso de reguladores vegetais no meio de cultura, ou pelo prolongado período de tempo em que a cultura permanece exposta a eles, pode provocar alterações genéticas, fisiológicas e morfológicas, resultando na redução da taxa de multiplicação e no encurtamento dos caules, o que dificulta a individualização das plantase o processo de enraizamento (Narayanaswamy, 1977).

Segundo Cantagallo et al. (2005), brotações provenientes de meio de cultura com concentrações menores de reguladores apresentaram desenvolvimento vegetativo superior. No presente trabalho não houve diferenças significativas entre as concentrações de BAP, com relação ao número de folhas das brotações (Tabela 2). Entretanto, a ausência desse regulador vegetal e a concentração de $2,0 \mathrm{mg} \mathrm{L}^{-1}$ resultaram em baixa produção de brotos em alumã (Figura 2). Da mesma forma, Andrade et al. (2006) verificaram que o aumento no número de brotações de Eucalyptus grandis foi inversamente proporcional ao aumento da dosagem e do tempo de exposição ao BAP.

$O$ efeito benéfico do BAP na multiplicação das brotações pode ser relacionado com a influência desse regulador na divisão celular e na quebra de dormência das gemas axilares, até então inibidas pela dominância apical (Brum et al., 2002). O mesmo foi observado com o alumã (Figura 3).

Durante o desenvolvimento das brotações de alumã mantidas em meio de cultura contendo BAP, observou-se a ocorrência de hiperhidricidade das folhas nos tratamentos com 3,0; 4,0 e 5,0 $\mathrm{mg} \mathrm{L}^{-1}$ de BAP (Figura 4). Pinto et al. (1994), trabalhando com segmentos nodais de Kielmeyera coriacea cultivados em meio de cultura MS suplementado com concentrações acima de $8,0 \mathrm{mg} \mathrm{L}^{-1}$ de BAP, também observaram a formação de brotações hiperhídricas.

A hiperhidricidade é um evento comum na

TABELA 2. Número de folhas, comprimento da parte aérea e comprimento da raiz de brotos de alumã em função de diferentes concentrações de BAP, após 75 dias de cultivo.

\begin{tabular}{cccc}
\hline $\begin{array}{c}\text { Concentração de } \\
\text { BAP }\left(\mathbf{m g ~ L}^{-1}\right)\end{array}$ & $\begin{array}{c}\text { Número de folhas } \\
(\%)\end{array}$ & $\begin{array}{c}\text { Comprimento da } \\
\text { parte aérea }(\mathbf{c m})\end{array}$ & $\begin{array}{c}\text { Comprimento da } \\
\text { raiz }(\mathbf{c m})\end{array}$ \\
\hline 0,0 & $8.25 \mathrm{a}^{*}$ & $8.18 \mathrm{a}$ & $9.75 \mathrm{a}$ \\
1,0 & $10.88 \mathrm{a}$ & $8.38 \mathrm{a}$ & $10.38 \mathrm{a}$ \\
2,0 & $10.0 \mathrm{a}$ & $6.94 \mathrm{a}$ & $7.63 \mathrm{a}$ \\
\hline
\end{tabular}

*Médias seguidas da mesma letra na coluna não diferem significativamente (Tukey 0,05$)$. 


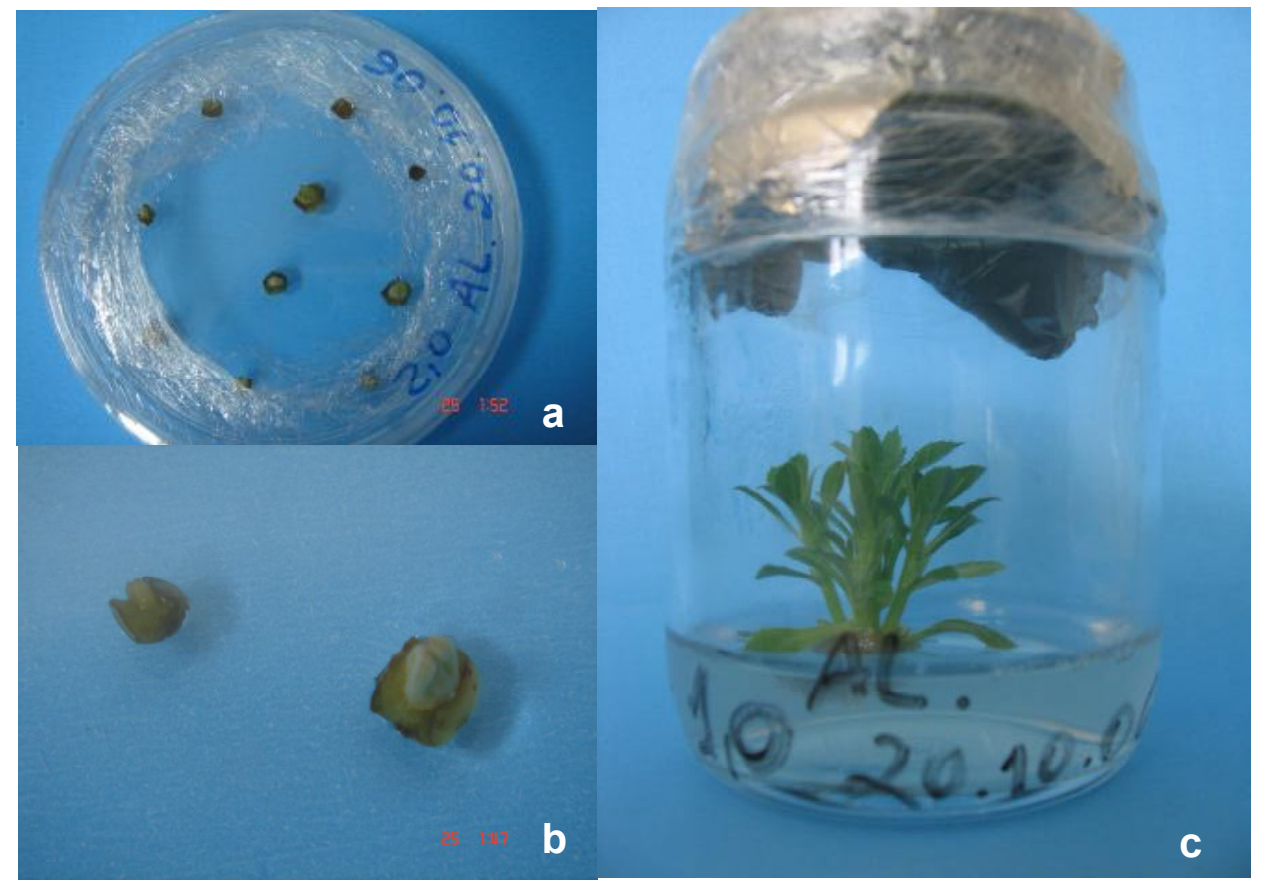

FIGURA 3. Multiplicação in vitro de Vernonia condensata Baker a partir de gemas axilares. a) Resposta das gemas após 15 dias de cultivo. b) Detalhe da gema. c) Brotações múltiplas provenientes da concentração $1,0 \mathrm{mg} \mathrm{L}^{-1}$.

cultura de tecidos, gerando anormalidades fisiológicas e morfológicas no tecido vegetal, afetando os processos de fotossíntese e trocas gasosas da planta (Ziv, 1991). Um dos fatores que provoca essa anormalidade é o excesso de regulador vegetal. As plantas quando estão com hiperhidricidade não são aptas a serem aclimatadas (Abreu et al., 2003).

Em algumas culturas, como a do alumã, as brotações obtidas na fase de multiplicação geralmente são pequenas e não se encontram em condições de serem individualizadas para o enraizamento, necessitando do uso de regulador vegetal que promova o alongamento da parte aérea dessas brotações.

A aplicação de 1,0 $\mathrm{mg} \mathrm{L}^{-1}$ de $\mathrm{GA}_{3}$ no meio de cultura conferiu um aumento na altura média das brotações provenientes dos tratamentos 0,$0 ; 1,0 \mathrm{e}$
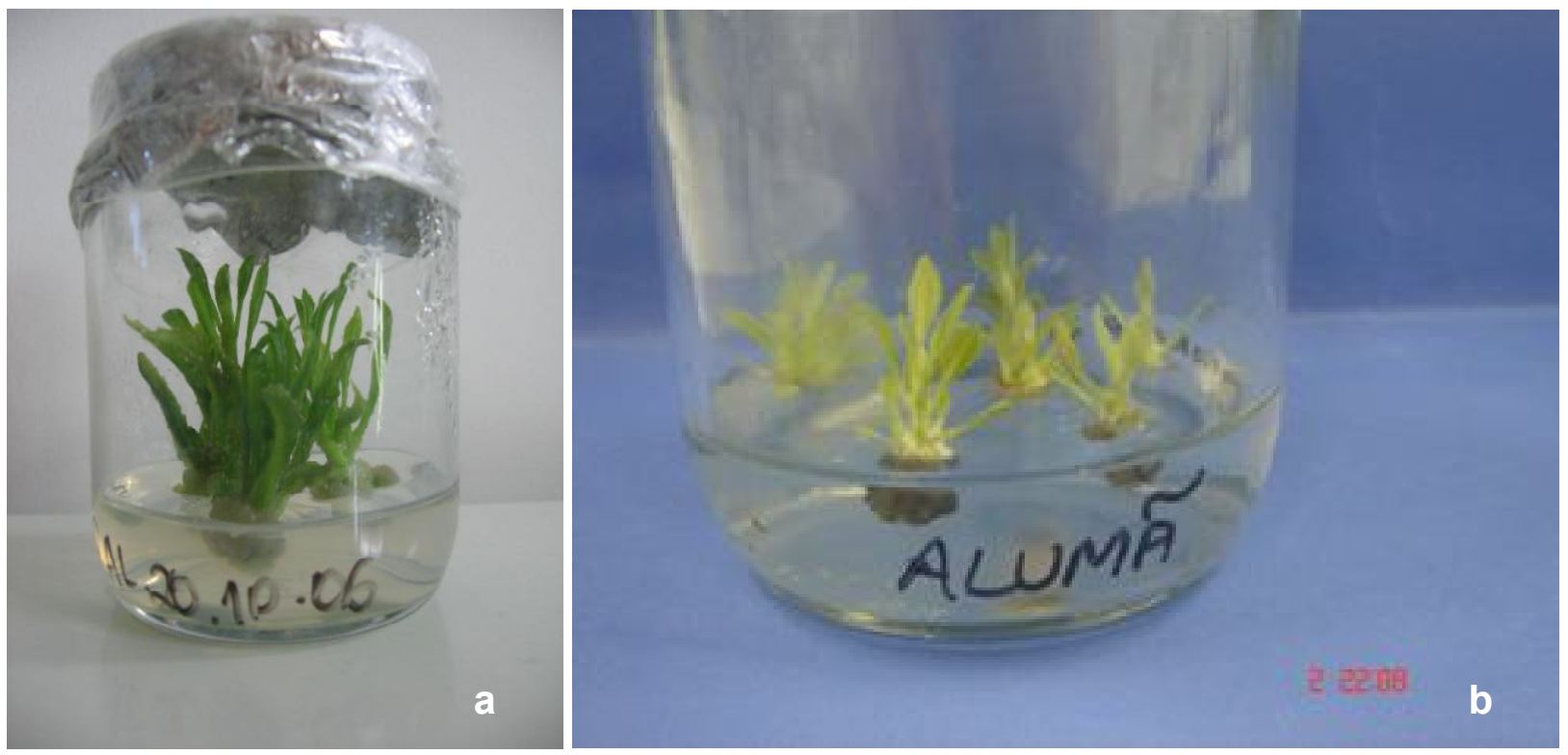

FIGURA 4. Hiperhidricidade observada em brotações in vitro de alumã. a) Brotações de alumã apresentando aspecto de hiperidricidade nas folhas em concentrações de 4,0 e 5,0 $\mathrm{mg} \mathrm{L}^{-1}$ de BAP. b) Hiperhidricidade na concentração de $3,0 \mathrm{mg} \mathrm{L}^{-1}$, onde o efeito foi menor. 
2,0 $\mathrm{mg} \mathrm{L}^{-1}$ (Figura 5), demonstrando o efeito benéfico promovido por este regulador no desenvolvimento in vitro de alumã. Os brotos com hiperhidricidade dos tratamentos 3,0; 4,0 e 5,0 $\mathrm{mg} \mathrm{L}^{-1}$ foram descartados. Segundo Grattapaglia \& Machado (1998), o efeito mais conhecido das giberelinas in vitro é no alongamento das partes aéreas quando essas não estão em condições de serem individualizadas para o enraizamento, devido ao seu pequeno tamanho. Grosser \& Gmitter Júnior (1990) também obtiveram alongamento satisfatório em plântulas de híbridos somáticos de citros, utilizando $1,0 \mathrm{mg} \mathrm{L}^{-1}$ de $\mathrm{GA}_{3}$ no meio de cultura.

O aumento do tamanho da muda proveniente da cultura de tecidos é de interesse prático, pois em razão do seu porte restrito, o manuseio torna-se mais difícil e o tempo para a produção comercial da muda é prolongado (Hoffmann et al., 2001).

O enraizamento das brotações é fundamental para a obtenção de plantas aclimatadas e em condições de serem transferidas para campo. A utilização de 1\% de carvão ativado no meio de cultura contendo $1,0 \mathrm{mg}$ $\mathrm{L}^{-1}$ de $\mathrm{GA}_{3}$ resultou no enraizamento das brotações de alumã, não havendo necessidade da adição de auxina (Figura 5). Ribeiro et al. (2000) estimularam o crescimento do sistema radicular em citros com 0,5 a $2,0 \mathrm{~g} \mathrm{~L}^{-1}$ de carvão ativado em cultivo in vitro.

Segundo Pasqual et al. (2001), o carvão ativado em concentrações de 0,2 a $3 \%$ pode ser utilizado para o enraizamento de diversas culturas. Fisicamente, ele simula a condição de escuro, no qual as raízes normalmente se desenvolvem melhor. Quimicamente, retém substâncias inibitórias do meio ou produtos tóxicos liberados pelos explantes e promove o crescimento de raízes.

Dois fatores podem ter contribuído ao bom enraizamento do alumã in vitro sem o emprego de regulador vegetal. O primeiro devido possivelmente à produção endógena de auxina pela planta. Segundo Coll et al. (1988), as partes aéreas são fontes de intensa produção de auxina que, ao ser translocada para a base, estimularia a rizogênese. Outro fator a ser considerado é o tamanho das raízes. Brotos pequenos em geral não enraízam bem necessitando, portanto, de uma fase intermediária adicional de alongamento com o uso do $\mathrm{GA}_{3}$. Deste modo, baseado no excelente enraizamento $(100 \%)$ obtido neste trabalho sem o uso de auxina, o tamanho dos explantes $(8$ a $13 \mathrm{~cm})$ utilizados neste experimento revelaram competência na formação de raiz (Figura $5 b$ ).

As microplantas de alumã apresentaram $100 \%$ de sobrevivência e bom desenvolvimento durante o processo de aclimatação (Figura 6), independente da concentração de BAP utilizada. Já Silva et al. (2003) concluíram em seu trabalho que plantas de gloxínias apresentaram maior número de plantas sobreviventes durante o processo de aclimatação, quando provenientes de cultivo in vitro com 1,0 $\mathrm{mg} \mathrm{L}^{-1}$ de BAP. Da mesma forma, Ribas et al. (2002) trabalharam com plantas de maracujazeiro provenientes de cultivo in vitro e verificaram que as concentrações de 1,0 e 2,0 $\mathrm{mg} \mathrm{L}^{-1}$ de BAP foram fundamentais para a aclimatação onde obtiveram taxa de sobrevivência em torno de $100 \%$, independente do meio de cultura utilizado.

Araújo et al. (2002) relataram que mudas de Aloe vera enraizadas in vitro apresentam 80 a $95 \%$ de sobrevivência na aclimatização, enquanto que naquelas desprovidas de sistema radicular a taxa de sobrevivência cai para $30 \%$. A obtenção de microplanta com sistema radicular bem desenvolvido é de grande importância para a sua sobrevivência e crescimento em novas condições ambientais, como as proporcionadas na aclimatação (Pio et al., 2002).

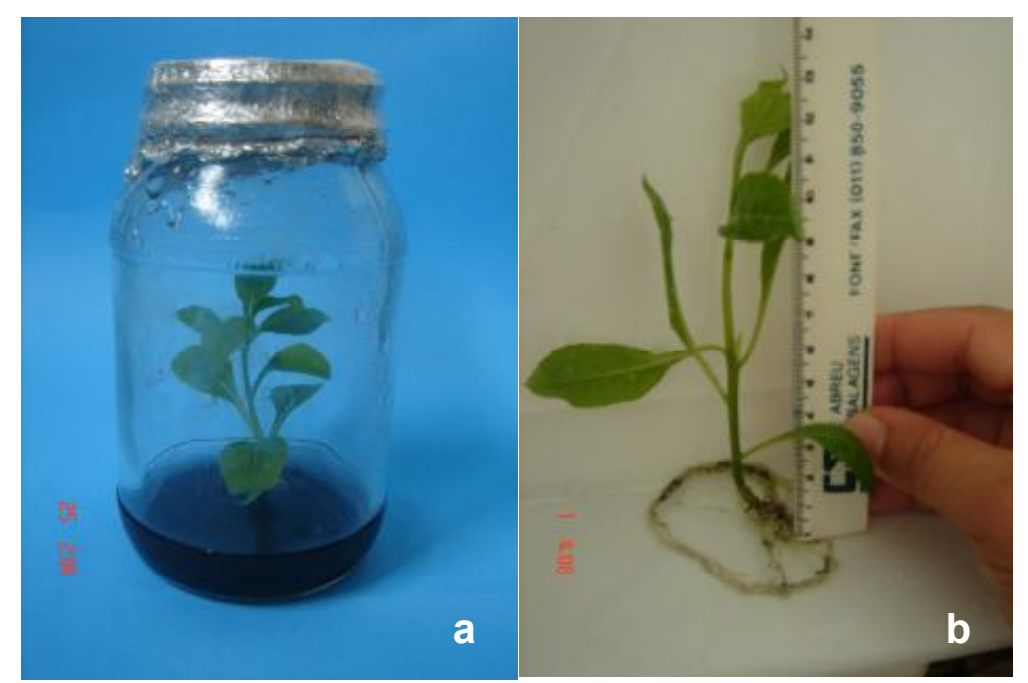

FIGURA 5. Alongamento e enraizamento de broto de alumã.a) MS contendo $\mathrm{GA}_{3}$ e carvão ativado, b) Avaliação dos parâmetros antes da aclimatação. 


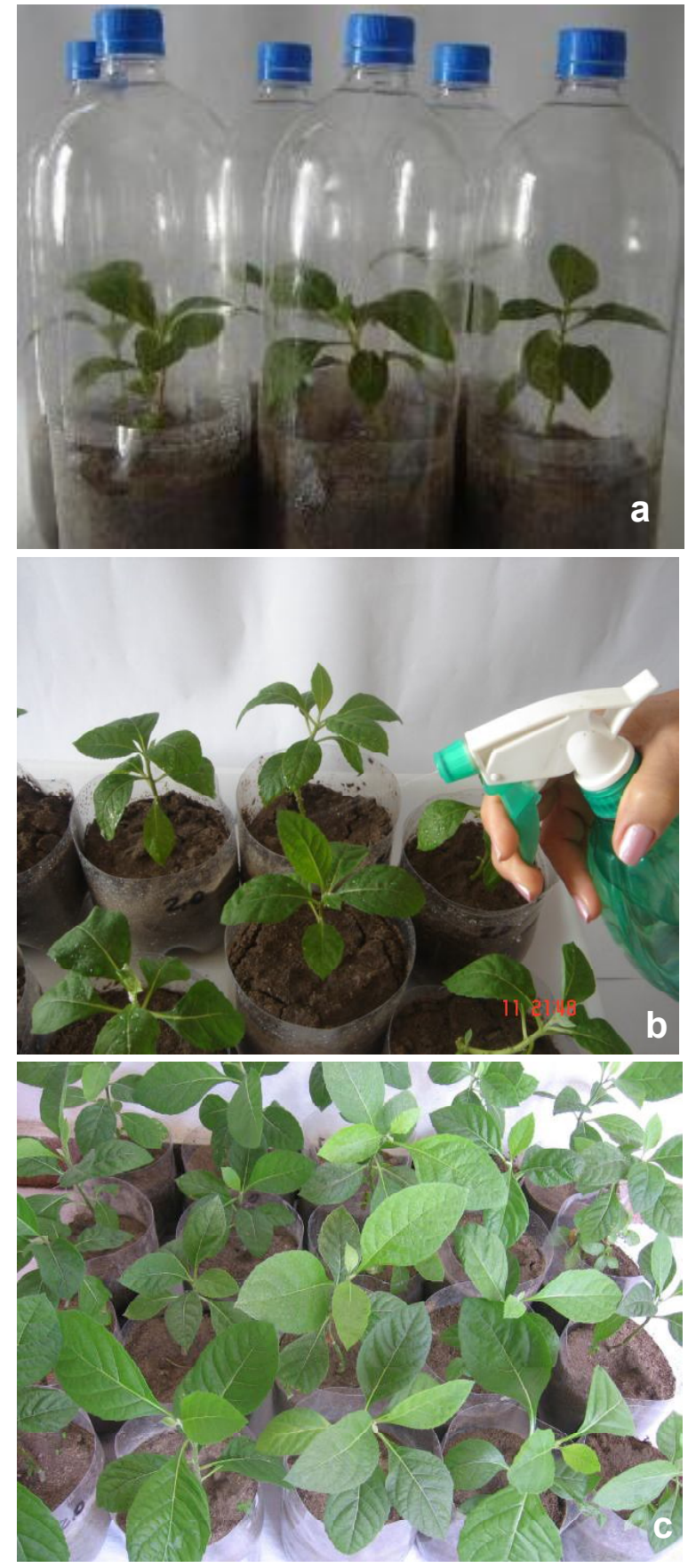

FIGURA 6. Aclimatação de microplantas de alumã: a) microplantas de alumã em garrafa PET; b) irrigadas com auxilio de borrifador; c) plantas totalmente aclimatadas.

A metodologia utilizada neste trabalho para a aclimatação das microplantas de alumã mostrouse eficiente e pode ser recomendada para a micropropagação desta espécie medicinal. Além disso, constitui-se numa alternativa de reciclagem para garrafas de refrigerante tipo PET, contribuindo para a sustentabilidade ambiental.

\section{CONCLUSÃO}

-A multiplicação in vitro de gemas axilares de Vernonia condensata Baker constitui-se em um processo possível e viável nas condições avaliadas.

-É possível micropropagar plantas de alumã, nas condições utilizadas neste trabalho, adicionandose a concentração de $1,0 \mathrm{mg} \mathrm{L}^{-1}$ de BAP no meio de cultura MS, na fase de multiplicação e acrescentar, no mesmo meio de cultura, 1,0 mg L-1 de $\mathrm{GA}_{3}$ e $1,0 \mathrm{~g}$ $\mathrm{L}^{-1}$ de carvão ativado para alongar e enraizar as brotações, bem como obter $100 \%$ de plantas aclimatadas.

\section{REFERÊNCIA}

ABREU, I.N. et al. Propagação in vivo e in vitro de Cissus sicyoides, uma planta medicinal. Acta Amazônica, v.33, n.1, p.1-7, 2003.

ANDRADE, W.F.; ALMEIDA, M.; GONÇALVES, A.N. Multiplicação in vitro de Eucalyptus grandis sob estímulo com benzilaminopurina. Pesquisa Agropecuária Brasileira, v.41, n.12, p.1715-9, 2006.

ARAUJO, P.S. et al. Micropropagação de babosa Aloe vera L. Biotecnologia Ciência e Desenvolvimento, v.5, n.25, p.54-7, 2002.

BAJAJ, Y.P.S.; FURMANOWA, M.; OLSZOWSK, O. Biotechnology of the micropropagation of medicinal and aromatic plants. Biotechnology in agriculture and foresty, v.4, p. 60-103, 1988.

BOORHEM, R.L. Segredos e virtudes das plantas medicinais. Rio de Janeiro: Reader's Digest Brasil Ltda., 1999. 416p.

BRUM, G.R.; SILVA, A.B.; PASQUAL, M. Efeito de diferentes concentrações de BAP e ANA na propagação in vitro da figueira (Fícus carica L.). Ciência Agrotécnica, v.26, n.2, ed.esp., p.1403-9, 2002.

CAMPOS, R.A.S. et al. Micropropagação de Jatropha elliptica (Pohl) Müll. Arg. Revista Brasileira de Plantas Medicinais, v.9, n.3, p.30-6, 2007.

CANTAGALLO, F.S. et al. Micropropagação de citrumelo 'Swingle' pelo cultivo in vitro de gemas axilares. Revista Brasileira de Fruticultura, v.27, n.1, p.136-8, 2005.

COLL, J.B. et al. Fisiologia vegetal. 6.ed. Madri: Pirâmide, 1988. 702p.

CRÓCOMO, O.J. Plant biotechnology in the agriculture and development in Brazil. In: SIMPÓSIO ANUAL DA ACADEMIADE CIÊNCIA DE SÃO PAULO, 11., 1986, São Paulo. Anais... São Paulo, 1986. p.53-71.

CUNHA, G.A.P.; CABRAL, J.R.S.; SOUZA, L.F.S. 0 abacaxiziero: cultivo, agroindústria e economia. Brasília: EMBRAPA, 1999. 480p.

GRATTAPAGLIA, D.; MACHADO, M.A. Micropropagção. In: TORRES, A.C.; CALDAS, L.S.; BUSO, J.A. (Eds.). Cultura de tecidos e transformação genética de plantas. Brasília: ABCTP/Embrapa-CNPH, 1998. p.402-38.

GROSSER, J.W.; GMITTER JÚNIOR, F.G. Protoplast fusion and citrus improvement. Plant Breeding Reviews, v.8, p.339-74, 1990.

HARARIKA, B.N. Acclimatization of tissue-cultured plants. Current Science, v.85, n.12, p.1704-12, 2003. 
HOFFMANN, A.; CHALFUN, N.N.J.; PASQUAL, M. Efeito do ácido giberélico e do frio na sobrevivência e crescimento inicial de plântulas micropropagadas de macieira 'Marubakaido', durante a aclimatização. Ciência e Agrotecnologia, v.25, n.1, p.31-7, 2001. HOFFMANN, A. Aclimatação de mudas produzidas in vitro e in vivo. Informe Agropecuário, v.23, n.216, p.21-4, 2002. LORENZI, H.; MATOS, F.J.A. Plantas medicinais no Brasil: nativas e exóticas. Instituto Plantarum, v.13, p.382-3, 2002. MALDANER, J. et al. Sacarose e nitrogênio na multiplicação in vitro de Pfaffia glomerata (Spreng.) Pedersen. Ciência Rural, v.36, n.4, p.1201-6, 2006. MURASHIGE, T.; SKOOG, F. A revised medium for rapid growth and bioassays with tobacco tissue cultures. Physiologia Plantarum, v.15, n.3, p.473-97, 1962. NAGAO, E.O.; PASQUAL, M.; RAMOS, J.D. Efeitos da sacarose e do nitrogênio inorgânico sobre a multiplicação in vitro de brotações de porta-enxerto de citros. Bragantia, v.53, n.1, p.25-31, 1994.

NARAYANASWAMY, S. Regeneration of plants from tissue cultures. In: REINERT, J.; BAJAJ, Y.P.S. Applied and fundamental aspects of plant cell tissue and organ cuture. Berlin: Springer Verlag, 1977. p.179-248.

NICOLOSO, F.T. et al. Micropropagação do ginseng brasileiro [Pfaffia glomerata (Spreng.) Pedersen]. Revista Brasileira de Plantas Medicinais, v.3, n.2, p.11-8, 2001. PASQUAL, M.; ANDO, A. Micropropragação de 'Trifoliata' através da cultura de gemas axilares in vitro. Pesquisa Agropecuária Brasileira, v.24, n.2, p.217-20, 1989. PASQUAL, M.; RAMOS, J.D.; DUTRA, L.F. Aplicações no melhoramento genético de plantas. 2001. 79p. Monografia (Especialização em Cultura de Tecidos Vegetais: tecnologia e aplicações) - Universidade Federal de Lavras, Lavras.

PINTO, J.E.B.P.; ARELLO, E.F.; PINTO, C.A.B.P. Uso de diferentes explantes e concentrações de benzilaminopurina na multiplicação in vitro de Kielmeyra coriaceae. Pesquisa Agropecuária Brasileira, v.29, n.6, p.867-73, 1994.

$\mathrm{PIO}$, R. et al. Enraizamento in vitro de brotações do porta enxerto de citros Tangerina sunki x Trifoliata English 63256 com o uso de sacarose e ácido indol-butírico. Ciência e Agrotecnologia, v.26, n.1, p.66-70, 2002.

RIBAS, A.F. et al. Misturas vitamínicas na regeneração do maracujazeiro amarelo (Passiflora edulis f. flavicarpa deg.). Ciência Rural, v.32, n.2, p.237-41, 2002.

RIBEIRO, V.G. et al. Efeitos de ácido giberélico e carvão ativado no cultivo in vitro de Citrus limonia Osbeck $\mathrm{x}$ Poncirus trifoliata (L.) Raf. Pesquisa Agropecuária Brasileira, v.35, n.1, p.27-30, 2000.

SCHEFFER, M.C. Roteiro para estudos de aspectos agronômicos das plantas medicinais selecionadas pela fitoterapia do SUSPR/ CEMEPR. Sob Informa, v.10, n.2, p.29-31, 1992.

SILVA, A.B. et al. BAP e substratos na aclimatização de plântulas de gloxínia (Sinningia speciosa Lood. Hiern.) provenientes de cultura de tecidos. Ciência Agrotécnica, v.27, n.2, p.255-60, 2003.

SOUZA, A.V. et al. Germinação de embriões e multiplicação in vitro de Lychnophora pinaster mart. Ciência Agrotécnica, v.27, n.2, ed. esp., p.1532-8, 2003. TAVARES, A.R.; CASTRO, C.E.F.; COSTA, A.M.M. Propagação in vitro de Alpinia purpurata (Vieill) K. Schum. In: CONGRESSO DA SOCIEDADE DE BOTÂNICA DE SÃO PAULO, 8., Campinas, 1990. Anais... São Paulo: SBSP, 1992. p.67-9.

ZIV, M. Vitrification: morphological and physiological disorders of in vitro plants. In: DEBERGH, P.C.; ZIMMERMAN, R.H. (Eds.) Micropropagation: technology and application. London: Kluwer Academic Publishers, 1991. p.45-69. 